\title{
Efficacy of reminiscence in cognition, depressive symptoms and quality of life in institutionalized elderly: a systematic review
}

\author{
Eficácia da reminiscência na cognição, sintomas depressivos e qualidade \\ de vida em idosos institucionalizados: revisão sistemática \\ Efectividad de la reminiscencia en la cognición, síntomas depresivos y \\ calidad de vida en ancianos institucionalizados: revisión sistemática
}

How to cite this article:

Gil I, Costa P, Parola V, Cardoso D, Almeida M, Apóstolo J. Efficacy of reminiscence in cognition, depressive symptoms and quality of life in institutionalized elderly: a systematic review. Rev Esc Enferm USP. 2019;53:e03458. DOI: http://dx.doi.org/10.1590/S1980-220X2018007403458

\author{
Isabel Gili,2 \\ Paulo Costa ${ }^{1,2}$ \\ Vítor Parola ${ }^{1,2,3}$ \\ Daniela Cardoso ${ }^{1,2,3}$ \\ Maria Almeida ${ }^{1,2}$ \\ João Apóstolo ${ }^{1,2,3}$ \\ ${ }^{1}$ Escola Superior de Enfermagem \\ de Coimbra, Coimbra, Portugal. \\ ${ }^{2}$ Unidade de Investigação em Ciências da \\ Saúde, Enfermagem, Coimbra, Portugal. \\ ${ }^{3}$ Portugal Centre for Evidence Based \\ Practice: A Joanna Briggs Institute Centre \\ of Excellence, Coimbra, Portugal.
}

\begin{abstract}
Objective: To identify the best available evidence on the efficacy of Reminiscence Therapy in cognition, depressive symptoms and quality of life in elderly individuals with cognitive impairment. Method: The methodology proposed by the Joanna Briggs Institute was used. Studies focused on group Reminiscence Therapy aimed at institutionalized elderly people with cognitive impairment aged 65 or over were considered. The critical analysis, extraction and synthesis of results was performed by two independent researchers. Results: Four randomized clinical trials and two quasi-experimental studies $(n=296)$ were included. Given the heterogeneous characteristics of studies found, it was impossible to perform a meta-analysis. Of the six studies included, two presented statistically significant results for efficacy in cognition, and three for efficacy in reducing depressive symptoms. In none of the studies was evaluated the elderly's quality of life. Conclusion: Reminiscence Therapy has potential efficacy for maintaining cognition and decrease of depressive symptomatology in the target population.
\end{abstract}

DESCRIPTORS

Aged; Cognition; Depression; Quality of Life; Review. 


\section{INTRODUCTION}

As a result of the higher average life expectancy, it is increasingly important to consider the scenarios of therapeutic intervention that positively influence aging and quality of life in old age based on the principles of person-centered care aimed at promoting human dignity. The deep demographic changes characterized by progressive population aging are associated with the increase of chronic degenerative diseases, such as neurocognitive disorders (NCD). These disorders are characterized by a commitment to the person's earlier level of functioning, especially in cognitive function ${ }^{(1)}$.

In this line of thought, the progressive loss of cognitive and motor capacities resulting from the degenerative process in more advanced states of the disease leads to a high sense of overload of the family and caregivers that often culminates in the elderly person's institutionalization ${ }^{(2)}$. As a consequence, there may be a gradual loss of social roles and functions, and the elderly may be profoundly affected by a set of limitations that further affect their learning ability, self-esteem, and relationship skills ${ }^{(3)}$. This process can minimize the abilities and social status of neurologically impaired older people ${ }^{(3)}$. The incidence and prevalence of depressive symptoms is also strongly associated with this reality, hence the consequent decrease in the elderly person's quality of life ${ }^{(4)}$.

Currently, there is still evidence limiting the spectrum of pharmacological therapy interventions used in the treatment of elderly people with cognitive impairment ${ }^{(5)}$, because traditional pharmacokinetic mechanisms only work on temporary control of symptomatology associated with the degenerative course of the pathology. Faced with these limits, in recent years, the focus of research has shifted to exploring the efficacy of non-pharmacological therapies for delaying the progression of cognitive impairment.

In the literature, Reminiscence Therapy (RT) emerges as an intervention with therapeutic potential through the recovery of significant life events with different designs and particular incidence in the resolution of conflicts of the past $^{(6)}$. RT involves pleasant and stimulating activities with the purpose of promoting the elderly person's self-esteem, identity and individuality ${ }^{(6)}$. Therefore, it has been reported as an intervention associated with pleasure, security and sense of belonging ${ }^{(7)}$.

This person-centered therapeutic approach values individuals' human dimension and life trajectory by mobilizing their still preserved cognitive resources. By resorting to the evocation of long-term memories, which generally remain intact, RT contributes to reducing the experience of failure often felt by elderly people with cognitive impairment ${ }^{(8)}$.

However, the implementation of non-pharmacological therapies, such as RT, alone or in combination with pharmacological therapies, implies the training of health professionals and respect for the best evidence-based practices $^{(9)}$. For this purpose, a preliminary research was conducted in the Cochrane Database of Systematic Reviews, in which was found one review on RT in elderly people with cognitive impairment ${ }^{(10)}$. The last study integrated in this review dates from May 2004. The aim were the effects of Reminiscence
Therapy in elderly people with dementia and their caregivers, more precisely, their well-being, depressive symptoms and quality of life, communication and interaction, cognition and impact on caregivers. The authors concluded that results of the efficacy of RT in people with cognitive impairment are promising and bring improvements to their cognition, depressive symptoms and behavior ${ }^{(10)}$.

In a more recent systematic review ${ }^{(11)}$, the authors conducted a meta-analysis of randomized controlled trials on the efficacy of RT in cognitive functions and reduction of depressive symptoms in elderly people with cognitive impairment. The most significant improvements found by authors were in depressive symptoms of institutionalized elderly people when compared to community residents. However, that review did not contemplate the evaluation of efficacy in domains intrinsically associated with cognitive function and depressive symptoms, such elderly people's quality of life. Equally important, is that such a review is unclear regarding inclusion criteria (for example, participants), repeats databases (MEDLINE and PubMed surveys), and uses unclear research strategies ${ }^{(11)}$.

There were no systematic reviews in this thematic scope registered in the PROSPERO international prospective register of systematic reviews.

Considering the limitations of the aforementioned systematic reviews ${ }^{(10-11)}$, the objective was to identify and synthesize the best available evidence on the efficacy of RT in cognitive function, depressive symptoms and quality of life of institutionalized elderly people with cognitive impairment.

To that end, was developed the following guiding question: "What is the efficacy of the group Reminiscence Therapy in the cognition, depressive symptoms and quality of life of institutionalized elderly people with cognitive impairment?".

\section{METHOD}

\section{TYPE OF STUDY}

This systematic review of the literature followed the reference methodology recommended by the Joanna Briggs Institute ${ }^{(12)}$.

\section{Population}

Inclusion/exclusion criteria for Population, Intervention, Comparison and Outcomes (PICO) were defined and applied. Participants: adults ( $\geq 65$ years) identified with cognitive impairment either through a formal clinical diagnosis documented by standardized neurological test, or by quantitative clinical evaluation. Intervention: group reminiscence programs aimed at institutionalized elderly people with cognitive impairment in residential structures. Comparison: All types of comparisons have been accepted, namely psychosocial interventions aimed at people with cognitive or habitual care impairment. Outcomes: cognition, depressive symptoms and quality of life evaluated with use of validated instruments. Only experimental studies (randomized controlled trials and quasi-experimental studies with or without control group) were considered. 


\section{DATA COLLECTION}

The research strategy included published and unpublished studies. A three-step search strategy was used. Initially, was performed a limited search in PubMed and CINAHL, followed by the analysis of terms used in the title and abstract, and indexation terms described in the articles.
Subsequently, was conducted a second search using all keywords and descriptors identified in all databases included (Chart 1). Finally, was analyzed the list of references of the identified articles in order to include additional studies.

Studies in English, Spanish and Portuguese were considered for inclusion in this review. The database search strategy covered the period between May 1, 2004 and April 2017.

Chart 1 - Search strategies applied by database - Coimbra, Portugal, 2017.

\begin{tabular}{|c|c|}
\hline $\begin{array}{c}\text { Database } \\
\text { (initial results by search) }\end{array}$ & Search formula \\
\hline $\begin{array}{l}\text { CINAHL Complete } \\
\text { via EBSCO } \\
(109)\end{array}$ & $\begin{array}{l}\text { (TI Reminiscence) OR (AB Reminiscence) OR (MH Reminiscence Therapy (lowa NIC)) OR ((MH Reminiscence Therapy } \\
))) \text { AND }(((\mathrm{TI} \text { Cognit*) OR (AB Cognit*)) OR ((TI "quality of life" ) OR (AB "quality of life" })) \text { OR ((TI depressi*) OR }(\mathrm{AB} \\
\text { depressi*)) OR ((TI mood) OR (AB mood)) OR ((MH Cognition )) OR ((MH Quality of Life)) OR ((MH Depression))) } \\
\text { AND (((TI dementia) OR (AB dementia)) OR ((TI alzheimer) OR (AB alzheimer)) OR ((TI "cognitive impairment" }) \\
\text { OR (AB "cognitive impairment")) OR ((TI "neurocognitive disorder") OR (AB "neurocognitive disorder")) OR ((TI } \\
\text { "neurocognitive disorders") OR (AB "neurocognitive disorders")) OR ((TI "cognitive decline") OR (AB "cognitive } \\
\text { decline")) OR ((MH Dementia))) }\end{array}$ \\
\hline PubMed (96) & $\begin{array}{l}\text { (dementia[Title/Abstract]) OR alzheimer[Title/Abstract]) OR "neurocognitive disorder"[Title/Abstract]) OR } \\
\text { "cognitive impairment"[Title/Abstract]) OR "neurocognitive disorders"[Title/Abstract]) OR "cognitive decline"[Title/ } \\
\text { Abstract]) OR "Dementia" [Mesh]) OR "Cognitive Dysfunction"[Mesh])) AND Reminiscence[Title/Abstract]) AND } \\
\text { (cognit*[Title/Abstract]) OR “quality of life"[Title/Abstract]) OR depressi*[Title/Abstract]) OR mood[Title/Abstract]) OR } \\
\text { "Cognition"[Mesh]) OR "Quality of Life"[Mesh]) OR "Depression"[Mesh]) }\end{array}$ \\
\hline $\begin{array}{l}\text { Cochrane Database of } \\
\text { Systematic Reviews (50) }\end{array}$ & $\begin{array}{l}\text { (Dementia:ti,ab,kw) OR (Alzheimer:ti,ab,kw) OR ("Cognitive impairment":ti,ab,kw OR ("neurocognitive } \\
\text { disorder:ti,ab,kw") OR ("cognitive decline":ti,ab,kw) OR [MH "Dementia"+] AND (reminiscence:ti,ab,kw) AND } \\
\text { (cognit*:ti,ab,kw) OR ("quality of life":ti,ab,kw) OR (depressi*:ti,ab,kw) OR (mood:ti,ab,kw) OR [MH "Cognition"+] OR } \\
{[\mathrm{MH} \text { "Quality of Life"+] OR [MH "Depression"+] }}\end{array}$ \\
\hline $\begin{array}{l}\text { Open Access Scientific } \\
\text { Repository of Portugal (75) }\end{array}$ & Full-Text:(Reminiscence) \\
\hline OpenGrey Repository (12) & ("Reminiscence") \\
\hline CAPES (35) & (Reminiscence) \\
\hline
\end{tabular}

\section{ANALYSIS AND PROCESSING OF DATA}

The methodological quality assessment of studies was performed independently by two reviewers using the standardized tools of the Joanna Briggs Institute. For randomized controlled trials, was used the Checklist for Randomized Controlled Trials, and for quasi-experimental studies was used the Checklist for Quasi-Experimental Studies ${ }^{(12)}$. Differences between reviewers were resolved by discussing with one another or by appealing to a third reviewer when necessary.

Given the scarcity of publications in this field, all studies that met the inclusion criteria were included in this review, and the methodological weaknesses in each study were discussed later.

Data were extracted by two independent reviewers with use of the standardized extraction tool from Joanna Briggs Institute for quantitative studies ${ }^{(12)}$. The extracted data focused on specific details regarding interventions, population, study designs and relevant results for the research question. The divergences found in this process were resolved through conversation between reviewers and a third reviewer was involved when necessary.

A meta-analysis was not performed given the significant differences between interventions, evaluated outcomes (clinical heterogeneity) and design (methodological heterogeneity) of the studies included. Thus, data will be presented in a narrative way and organized according to the outcomes of interest. This process was performed equally by two independent reviewers.

\section{RESULTS}

Initially, were identified 377 potentially relevant studies. Of these, 98 were excluded because they were duplicated; of the remaining 279 , were excluded 248 after evaluation of title and abstract. Of the remaining 31 articles, were excluded 25 because they did not meet the inclusion criteria after reading the text in full. Finally, was evaluated the methodological quality of the remaining six studies included in the review. The selection process of the studies is shown in a flowchart (Figure 1).

All studies included were published between 2007 and 2015 in English and performed in nursing homes and longstay health units. Two of the studies are from Japan, and the remaining four are from Italy, Turkey, Spain and the Republic of China.

Regarding the methodological quality of the included randomized controlled trials, only three out of the 13 questions of the critical appraisal tool were performed in all (Chart 2). In all studies, it is unclear whether the allocation to treatment groups was concealed from participants, if outcomes were reliably assessed, and if the study design was appropriate to the research domain. Thus, these aspects and other possible deviations were taken into account when performing the analysis of results. In one of the studies included $^{(13)}$, was not performed a true randomization of participants in the assignment to intervention groups. On the other hand, in another study ${ }^{(14)}$, the professionals who conducted the interventions were not kept blinded to the allocation of participants by groups. 


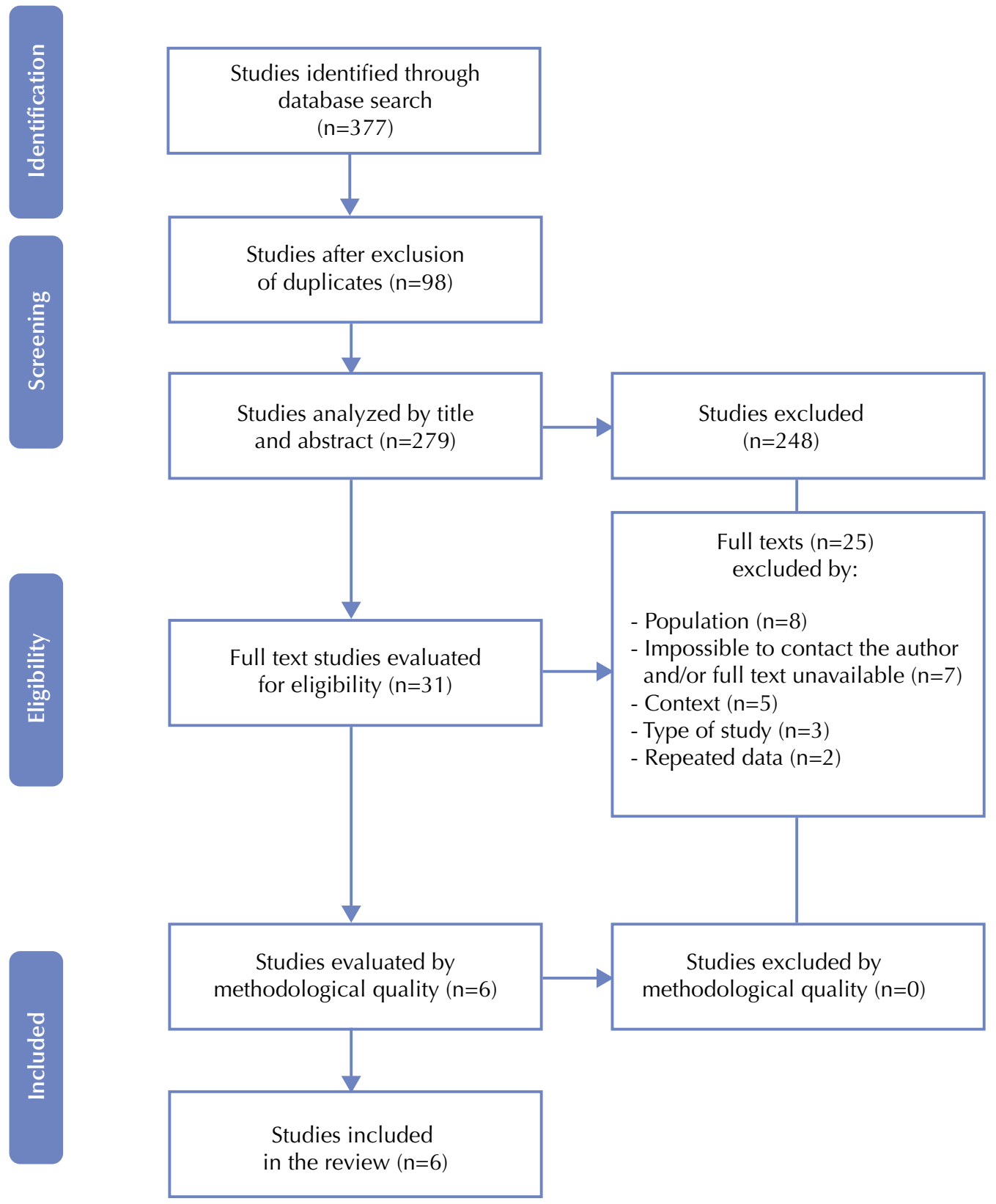

Figure 1 - Flowchart of the search and selection process of studies - Coimbra, Portugal, 2017.

Chart 2 - Methodological quality assessment of randomized controlled trials.

\begin{tabular}{|l|c|c|c|c|}
\hline \multicolumn{1}{|c|}{ Question } & Wang & Nakamae et al. ${ }^{(14)}$ & Akanuma et al.(15) & \multicolumn{1}{c|}{$\begin{array}{c}\text { Deponte \& } \\
\text { Missan }\end{array}$} \\
\hline 1. Was true randomization used for assignment to treatment groups? & No & Unclear & Unclear & Unclear \\
\hline 2. Was allocation to groups concealed? & Unclear & Unclear & Yes & Unclear \\
\hline 3. Were treatment groups similar at the baseline? & Yes & Yes & Yes & Yes \\
\hline 4. Were participants blind to treatment assignment? & Unclear & Unclear & Unclear & Unclear \\
\hline 5. Were those delivering treatment blind to treatment assignment? & Unclear & No & Unclear & Unclear \\
\hline 6. Were outcomes assessors blind to treatment assignment? & Yes & Unclear & Yes & Unclear \\
\hline $\begin{array}{l}\text { 7. Were treatment groups treated identically other than the } \\
\text { intervention of interest? }\end{array}$ & Unclear & Yes & Yes & Unclear \\
\hline
\end{tabular}




\begin{tabular}{|c|c|c|c|c|}
\hline Question & Wang $^{(13)}$ & Nakamae et al. ${ }^{(14)}$ & Akanuma et al. ${ }^{(15)}$ & $\begin{array}{l}\text { Deponte \& } \\
\text { Missan }^{(16)}\end{array}$ \\
\hline $\begin{array}{l}\text { 8. Was the follow up complete and if not, were adopted strategies to } \\
\text { correct its absence? }\end{array}$ & Unclear & Yes & Yes & Yes \\
\hline $\begin{array}{l}\text { 9. Were participants analyzed in the groups to which they were } \\
\text { randomized? }\end{array}$ & Yes & Yes & Yes & Yes \\
\hline 10. Were outcomes measured in the same way for all groups? & Yes & Yes & Yes & Yes \\
\hline 12. Was appropriate statistical analysis used? & Yes & Unclear & Unclear & Yes \\
\hline $\begin{array}{l}\text { 13. Is the study design appropriate to the topic under analysis, and any } \\
\text { deviations were accounted for in the conduct and analysis of the trial? }\end{array}$ & Unclear & Unclear & Unclear & Unclear \\
\hline
\end{tabular}

In the two quasi-experimental studies included in the review, six out of the nine questions in the critical appraisal tool were respected (Chart 3). In one of the studies $^{(17)}$, it is unclear if differences between groups were adequately described and analyzed during the course of the study. Equally relevant, it is uncertain if the statistical analysis employed in the two studies is appropriate to the design.

Chart 3 - Methodological quality assessment of the quasi-experimental studies.

\begin{tabular}{|l|c|c|}
\hline \multicolumn{1}{|c|}{ Question } & Gonzalez et al. ${ }^{(17)}$ & Așiret \& Kapucu ${ }^{(18)}$ \\
\hline 1. Is it clear in the study what is the cause and what is the effect? & Yes & Yes \\
\hline 2. Were the participants included in any comparisons similar? & Yes & Yes \\
\hline $\begin{array}{l}\text { 3. Were the participants included in any comparisons receiving similar } \\
\text { treatment/care other than the exposure or intervention of interest? }\end{array}$ & Yes \\
\hline 4. Was there a control group? & Yes & Yes \\
\hline $\begin{array}{l}\text { 5. Were there multiple measurements of the outcome pre and post the } \\
\text { intervention/exposure? }\end{array}$ & Yes & Yes \\
\hline $\begin{array}{l}\text { 6. Was follow up complete and if not, was follow up adequately } \\
\text { described and were used strategies to deal with the loss? }\end{array}$ & Unclear \\
\hline $\begin{array}{l}\text { 7. Were the outcomes of participants included in any comparisons } \\
\text { measured in the same way? }\end{array}$ & Yes & Yes \\
\hline 8. Were the outcomes measured in a reliable way? & Unclear & Unclear \\
\hline 9. Was appropriate statistical analysis used? & Unclear & Unclear \\
\hline
\end{tabular}

\section{CHARACTERISTICS OF PARTICIPANTS}

The number of participants under study varied between $24^{(15)}$ and $102^{(13)}$ (pre-intervention), and there were 296 individuals in total. In most studies, were recruited participants with different types of dementia, including Alzheimer's disease and ischemic vascular dementia. In two studies, were adopted standardized diagnostic criteria (as available in the $4^{\text {th }}$ Edition of the Diagnostic and Statistical Manual of Mental Disorders in Alzheimer's Disease Diagnostic and Treatment Centers) in order to identify eligible participants ${ }^{(14,17)}$. In four studies, were included participants based on the scores obtained in the Mini-Mental State Examination (MMSE): between 10 and 24 points $^{(15,18)}$; equal to or less than 23 points $^{(14)}$ or less than 23 points ${ }^{(17)}$.

\section{CHARACTERISTICS OF INTERVENTIONS AND EXPERIMENTAL GROUPS}

Five studies ${ }^{(13-15,17-18)}$ described in detail the structure and thematic content addressed in the RT group. In four studies, the thematic approach per session was similar, and the first session of the program served for the integration of participants and explanation of the intervention purpose $\mathrm{e}^{(13,15,17-18)}$.
The following sessions evoked past memories in an ascending chronological approach (childhood, youth and adulthood), although there were specific sessions for cross-cutting themes throughout life (occupations, family and friends, holidays and celebrations or travel). In order to facilitate recall of past memories, authors have used old photographs and personal objects, images, music and videos from other times, as well as specific foods and aromas. In one of the studies reviewed ${ }^{(14)}$, by remembering past memories, participants made an association with the activity of making traditional Chinese rice balls, and there was no organized sequence in the approach to different themes. Finally, in one of the studies ${ }^{(16)}$, the authors alluded to the implementation of sensory reminiscence sessions, although it was unclear how these were operationalized. In this sense, the original authors of this study were contacted, but additional clarifications were not provided.

Regarding the number of RT sessions, the total mean was 12 sessions, ranging from six ${ }^{(14)}$ to 24 sessions $^{(16)}$. The scheduled sessions were held weekly with an only exception $^{(16)}$ that was held twice a week. Sessions lasted between $30^{(18)}$ and $60^{(13,17)}$ minutes each, in a programmed total between 240 and 1.080 minutes ( $\bar{X}=580$ minutes). 
Regarding control groups, they were included in all studies. In four studies, participants received the usual care from their institution, in spite of no clear description of such care by any of the authors ${ }^{(13,15-17)}$. In one study ${ }^{(18)}$, participants in the control group were invited to attend thematic discussion sessions once a week for 20-25 minutes in which they discussed themes that did not involve recalling past memories. In another study ${ }^{(14)}$, participants in the control group were invited for meals, and were served rice balls prepared by participants in the RT group, an activity that did not involve recalling past memories. Only a single study ${ }^{(16)}$ included a comparison group with a specific therapeutic intervention, in which nine participants were included in a Validation Therapy group (with duration and frequency equal to the RT group). However, the authors did not present a clear description of how the activities were operationalized in Validation Therapy sessions ${ }^{(16)}$.

\section{Cognition}

In five studies ${ }^{(13-16,18)}$, was evaluated the impact of RT on cognitive function, and the MMSE was used transversally as an evaluation instrument. In one study ${ }^{(14)}$, was used the translated and validated version for the Japanese population, while in another study ${ }^{(13)}$, the version has been translated and validated for the Chinese population.

In one of the randomized controlled trials ${ }^{(15)}$, there were no statistically significant differences between groups in the period after the intervention, even though the overall scores were slightly better. With similar results, in another randomized controlled trial ${ }^{(14)}$, no significant changes in cognitive function were found between groups. In turn, according to results obtained by other authors ${ }^{(16)}$, no significant differences were found between the RT group, the Validation Therapy group and the control group pre- and post-intervention. However, only in the RT group the MMSE scores increased significantly in this period $(Z=$ $-2.05 ; \mathrm{p}<0.05)$.

In contrast, in a quasi-experimental study ${ }^{(18)}$, there was a statistically significant increase in mean MMSE scores in the RT group compared to the control group $(\mathrm{p}<0.05)$. However, in the RT group, no differences were found in the mean scores between individuals with different levels of cognitive impairment. In another study ${ }^{(13)}$, the RT group showed significant improvements in cognitive function compared to the pre-test $(p=0.015)$. But the elderly in the control group experienced a slight decrease in MMSE scores between the pre-and post-intervention period ${ }^{(13)}$.

\section{Depressive symptomatology}

In five studies, were evaluated the depressive symptoms participants, most commonly using the Geriatric Depression Scale (GDS) $)^{(13,15,18)}$ and the Cornell Scale for Depression in Dementia (CSDD) ${ }^{(13-14)}$. The Multidimensional Observation Scale for Elderly Subjects (MOSES) and the Center for Epidemiological Studies Depression Scale (CES-D) were used only in a randomized controlled trial ${ }^{(14)}$ and in a quasiexperimental study ${ }^{(17)}$, respectively.
In one of the studies included in the review ${ }^{(15)}$, there was an increase in the total scores in RT and control groups, but without statistical relevance. Conversely, other authors ${ }^{(18)}$ found a statistically significant decrease in mean GDS scores in the intervention group compared to the control group $(\mathrm{p}<0.05)$.

In a slighter way and using the 15 -item version of the GDS, in a study ${ }^{(13)}$ there was a decrease in scores between the pre- and post-intervention period $(\mathrm{F}=0.242 ; \mathrm{p}=0.12)$. Additionally, when using the CSDD scale for the evaluation of the same domain, there was a significant improvement for elderly subjects in the RT group compared to the preintervention evaluation $(\mathrm{p}=0.026)$.

By using the same scale (CSDD) and the MOSES scale, no significant differences were found between groups in the pre- and post-intervention period in one of the randomized controlled trials ${ }^{(14)}$. However, the early morning awakening subscale of the CSDD revealed statistically significant differences between groups ( $\mathrm{p}=0.046$ ), and participants in the RT group showed better overall results ${ }^{(14)}$.

In a study conducted by other authors ${ }^{(17)}$, the RT group presented a statistically significant reduction of depressive symptoms when compared to the control group $(\mathrm{F} 1.40=6.76$; $\left.\mathrm{p}=0.015 ; \mathrm{n}^{2}=0.213\right)$. When analyzing the evolution of each group independently, there was a significant decrease in the depressive symptomatology of participants in the RT group (F1.40=10.56; $\mathrm{p}=0.003 ; \mathrm{n}^{2}=0.150$ ), which was not observed in the control group ${ }^{(17)}$.

Transversally, the evaluation of all outcomes occurred between the pre- and post-intervention period, and intermediate or follow up evaluations were not performed in any of the included studies. Finally, in none of the included studies were evaluated the effects of RT on participants' quality of life.

\section{DISCUSSION}

This systematic review aimed to synthesize existing evidence on the efficacy of Reminiscence Therapy in institutionalized elderly people with cognitive impairment. The RT focuses on the recollection of elderly people's life events with use of stimuli such as photographs, music, videos, images or materials and equipment of the past. There is evidence of the growing interest in the implementation of RT in institutional contexts. Nowadays, care centered on elderly people with cognitive impairment is considered synonymous with excellence and quality ${ }^{(19)}$. Through RT, health professionals are in systematic contact with the life histories of the elderly, and learn in depth about their personality and preferences, which is invaluable information that fosters the development of truly individualized care. This approach allows the promotion of values such as freedom of choice, effective communication and focus on the potential of elderly people with cognitive impairment, and these factors influence their self-image and self-concept ${ }^{(20)}$.

In most studies included in this review, the approach to RT adopted was a structured program focused on the evocation and sharing of memories associated with general themes (childhood, old songs, festive times, family, among others) 
and use of personal objects and photographs to facilitate recollections. The generic themes used as a starting point for recalling memories may not always be adjusted to the interests and life course of each participant, which may explain some of the divergent results found.

Regarding the effects of RT implementation on cognition, its evaluation was performed transversally with use of the MMSE, in spite of the lack of a clear justification for its use by the authors. As RT focuses on the elderly's autobiographical memories, the use of an instrument sensitive to this cognitive domain should be considered in order to thoroughly evaluate the therapeutic potential of the intervention. The use of less sensitive instruments may underlie some of the less consistent results found. RT allows the elderly to remember past experiences and previously learned knowledge, skills and strategies. When faced with this list of experiences, elderly people evaluate them in a complex cognitive effort that tends to culminate with general improvements in this domain.

Regarding depressive symptoms, the institutionalized elderly can experience negative emotions due to their difficulty in adapting to the new institutional contexts. Group RT dynamics enhances socialization and interaction skills, based on the sharing of meaningful experiences that can contribute to a better psychological well-being ${ }^{(6)}$.

Some key points of this review should be considered in the development of future research. First, the selection of variables and measures of appropriate outcomes that reflect the intent of the intervention and respect the identity of institutionalized elderly with cognitive impairment. In none of the included studies was evaluated the elderly's quality of life, even though this domain is profoundly affected by the progression of the cognitive impairment and institutionalization of the elderly person.

Equally relevant is that all studies evaluated the potential effects of RT in the pre- and post-intervention period without a follow up evaluation. Thus, it was impossible to analyze if the effects of RT persist over time and act as a maintenance tool in the medium and long term for elderly people with cognitive impairment.

The inclusion of studies with small populations may explain some of the less consistent results found. Despite the high prevalence of the phenomenon under study, the access to participants with the desired inclusion characteristics is delicate. Furthermore, in terms of institutional management, the development of interventions such as group RT can generate considerable costs for institutions, such as: the allocation of health professionals who lead the sessions, availability of materials and equipment needed to recall memories and the existence of adequate spaces and privacy for conducting the therapy. These difficulties may explain the lack of prolonged studies with post-intervention follow up evaluations.

Non-pharmacological interventions such as RT require considerable exposure times in order to reach measurable potential effects. Therefore, the number of sessions, frequency, duration and approach of sessions developed in the different studies may have influenced the results obtained in the post-intervention period.
Reminiscence, as a therapeutic intervention, requires formation and training in its implementation and development, and can be implemented by health professionals and researchers in different contexts of care ${ }^{(19)}$. In the included studies, data on the training course of RT sessions professionals (such as hours of previous training) was unclear, which may have influenced the results obtained.

Still in this line, in none of the studies, RT sessions were conducted by nurses, although the studies have been developed in institutions where their presence is common (or in some cases, mandatory). By recognizing the privileged contact between nurses and elderly people (and their life course) and nurses' skills for applying this type of therapeutic intervention, further studies should be conducted to explore their role as professionals for conducting such sessions in this therapeutic field.

Traditionally, nurses' care provision to institutionalized elderly with cognitive impairment aligns with assumptions inherent to the biomedical model with procedures for the relief or compensation of functional injuries and disadvantages. The implementation and development of RT programs by nurses is in line with the paradigmatic transformation currently under way, with a shift towards person-centered and holistic care. However, the financial costs associated with non-pharmacological interventions such as RT are commonly used by the management as a reason for nonimplementation and development of these programs ${ }^{(21)}$. Skilled professionals, such as nurses, are pushed to focus on care delivery that involves highly differentiated and complex knowledge or procedures in these contexts. Compared to other non-pharmacological therapies or purely pharmacological interventions, remains the evidence that RT is a low-cost therapeutic intervention in its implementation and development ${ }^{(20)}$.

While limitations of this review, there was a significant heterogeneity of studies regarding their objectives, methodological design and sample, which made the meta-analysis of data impossible. The different approaches to group RT may have limited the analysis, comparison and synthesis of data.

During the drafting of the review protocol, the specific inclusion of institutionalized people aged 65 or older with cognitive impairment may have contributed to the loss of studies with valid data. However, this inclusion criterion is supported by a broad definition accepted and used by the scientific community, which stipulates that in developed countries, subjects aged 65 years or more are considered elderly ${ }^{(22)}$.

Even though experimental studies offer contributions of greater quality and scientific rigor, the exclusion of other studies within this scope also seems like a limitation of this review. In the same line of thought, the inclusion of studies in English, Portuguese and Spanish may have limited the number of results that met the inclusion criteria. In addition, no search was performed on databases related to psychology, and on websites of professional organizations, which may also have limited the number of final findings.

Future systematic reviews should address the weaknesses identified and develop a more comprehensive research 
strategy that obtains a greater number of studies. However, this review presents clinically significant contributions that are useful for health professionals who provide care for institutionalized elderly people with cognitive commitment.

\section{CONCLUSION}

The results suggest that RT may be an effective intervention in maintaining cognitive function and reducing depressive symptoms in institutionalized elderly people with cognitive impairment. In studies where there were significant improvements, participants included in the reminiscence group presented higher rates in these domains when compared to other non-pharmacological interventions, namely validation therapy, or control groups in which usual care or energized thematic discussions were performed.

However, the effects of RT on cognitive functions and depressive symptoms may have been influenced by the reduced size or distinct characteristics of the study samples, or by approaches to reminiscence that are different in their content, frequency, and duration. Additionally, there were no studies evaluating the efficacy of RT in the quality of life of institutionalized elderly people with cognitive impairment. The lack of studies with post-intervention follow up evaluation precludes any consideration of the duration of the therapeutic effect reported in some of the included studies. New research efforts should be undertaken with methodological approaches that fill these gaps.

As the group reminiscence therapy intervention is easily planned, implemented, and evaluated, health professionals should consider its inclusion in the therapeutic approach to elderly individuals with cognitive impairment. RT is a person-centered approach in which is recognized their individuality and dignity, and these values should be appreciated and privileged in an institutional context.

\section{RESUMO}

Objetivo: Identificar a melhor evidência disponível sobre a eficácia da Terapia de Reminiscência na cognição, sintomatologia depressiva e qualidade de vida em idosos com compromisso cognitivo. Método: Utilizou-se da metodologia proposta pelo Joanna Briggs Institute. Foram considerados estudos centrados na Terapia de Reminiscência em grupo, dirigida a pessoas idosas com idade superior ou igual a 65 anos, com compromisso cognitivo e institucionalizadas. A análise crítica, extração e síntese de resultados foi desenvolvida por dois investigadores independentes. Resultados: Foram incluídos quatro ensaios clínicos randomizados e dois estudos quasi-experimentais ( $n=296)$; as características heterogéneas dos estudos encontrados impossibilitaram a metanálise. Dos seis estudos incluídos, dois apresentaram resultados estatisticamente significativos para a eficácia na cognição e três para a eficácia na redução de sintomatologia depressiva. Em nenhum dos estudos foi avaliada a qualidade de vida dos idosos. Conclusão: A Terapia de Reminiscência apresenta potencial eficácia na manutenção da cognição e diminuição da sintomatologia depressiva na população-alvo.

\section{DESCRITORES}

Idoso; Cognição; Depressão; Qualidade de Vida; Revisão.

\section{RESUMEN}

Objetivo:Identificar la mejor evidencia disponible acerca de la efectividad de la Terapia de Reminiscencia en la cognición, sintomatología depresiva y calidad de vida en ancianos con compromiso cognitivo. Método: Se utilizó la metodología propuesta por el Joanna Briggs Institute. Fueron considerados estudios centrados en la Terapia de Reminiscencia en grupo, dirigida a personas mayores con edad superior o igual a 65 años, con compromiso cognitivo e institucionalizadas. El análisis crítico, extracción y síntesis de resultados los desarrollaron dos investigadores independientes. Resultados: Fueron incluidos cuatro ensayos clínicos randomizados y dos estudios cuasi-experimentales ( $n=296$ ); las características heterogéneas de los estudios encontrados imposibilitaron el metaanálisis. De los seis estudios incluidos, dos presentaron resultados estadísticamente significativos para la efectividad en la cognición y tres para la efectividad en la reducción de sintomatología depresiva. En ninguno de los estudios se evaluó la calidad de vida de los ancianos. Conclusión: La Terapia de Reminiscencia presenta potencial efectividad en el mantenimiento de la cognición y disminución de la sintomatología depresiva en la población meta.

\section{DESCRIPTORES}

Anciano; Cognición; Depresión; Calidad de Vida; Revisión.

\section{REFERENCES}

1. American Psychological Association. Diagnostic and statistical manual of mental disorders. 5th ed. Arlington: American Psychiatric; 2013.

2. Kuske B, Luck T, Hanns S, Matschinger H, Angermeyer M, Behrens J, et al. Training in dementia care: a cluster-randomized controlled trial of a training program for nursing home staff in Germany. Int Psychogeriatr. 2009;21(2):295-308.

3. Hughes J, Beatty A. Understanding the person with dementia: a clinicophilosophical case discussion. Adv Psychiatr Treat. 2013;19(5):33743.

4. Heser K, Wagner M, Wiese B, Prokein J, Ernst A, König H, et al. Associations between dementia outcomes and depressive symptoms, leisure activities, and social support. Dement Geriatr Cogn Dis Extra. 2014;4(3):481-93.

5. Cotelli M, Manenti R, Zanetti O. Reminiscence therapy in dementia: a review. Maturitas. 2012;72(3):203-5.

6. Dempsey L, Murphy K, Cooney A, Casey D, O'Shea E, Devane D, et al. Reminiscence in dementia: a concept analysis. Dementia. 2012;13(2):176-92.

7. Cappeliez P, O'Rourke N. Empirical validation of a model of reminiscence and health in later life. J Gerontol B Psychol Sci Soc Sci. 2006;61(4):P237-44.

8. Thorgrimsen L, Schweitzer P, Orrell M. Evaluating reminiscence for people with dementia: a pilot study. Arts Psychother. 2002;29(2):93-7. 
9. World Health Organization. Department of Mental Health and Substance Abuse. Mental Health Action Plan: 2013 - 2020. Geneva: WHO; 2013.

10. Woods B, Spector A, Jones C, Orrell M, Davies S. Reminiscence therapy for dementia. Cochrane Database Syst Rev. 2005;(2):CD001120.

11. Huang H, Chen Y, Chen P, Huey-Lan Hu S, Liu F, Kuo Y, et al. Reminiscence therapy improves cognitive functions and reduces depressive symptoms in elderly people with dementia: a meta-analysis of randomized controlled trials. J Am Med Dir Assoc. 2015;16(12):1087-94.

12. Tufanaru C, Munn Z, Aromataris E, Campbell J, Hopp L. Systematic reviews of effectiveness. In: Aromataris E, Munn Z. The Joanna Briggs Institute reviewer's manual. Adelaide: JBI; 2017.

13. Wang J. Group reminiscence therapy for cognitive and affective function of demented elderly in Taiwan. Int J Geriatr Psychiatry. 2007;22(12):1235-40.

14. Nakamae T, Yotsumoto K, Tatsumi E, Hashimoto T. Effects of productive activities with reminiscence in occupational therapy for people with dementia: a pilot randomized controlled study. Hong Kong J Occup Th. 2014;24(1):13-9.

15. Akanuma K, Meguro K, Meguro M, Sasaki E, Chiba K, Ishii H, et al. Improved social interaction and increased anterior cingulate metabolism after group reminiscence with reality orientation approach for vascular dementia. Psychiatry Res Neuroimaging. 2011;192(3):183-7.

16. Deponte A, Missan R. Effectiveness of validation therapy (VT) in group: preliminary results. Arch Gerontol Geriatr. 2007;44(2):113-7.

17. Gonzalez J, Mayordomo T, Torres M, Sales A, Meléndez J. Reminiscence and dementia: a therapeutic intervention. Int Psychogeriatr. 2015;27(10):1731-7.

18. Aşiret G, Kapucu S. The effect of reminiscence therapy on cognition, depression, and activities of daily living for patients with Alzheimer disease. J Geriatr Psychiatry Neurol. 2015;29(1):31-7.

19. Van Bogaert P, Tolson D, Eerlingen R, Carvers D, Wouters K, Paque K, et al. SolCos model-based individual reminiscence for older adults with mild to moderate dementia in nursing homes: a randomized controlled intervention study. J Psychiatr Ment Health Nurs. 2016;23(910):568-575.

20. Subramaniam P, Woods B. The impact of individual reminiscence therapy for people with dementia: systematic review. Expert Rev Neurother. 2012;12(5):545-55.

21. Kirkley C, Bamford C, Poole M, Arksey H, Hughes J, Bond J. The impact of organisational culture on the delivery of person-centred care in services providing respite care and short breaks for people with dementia. Health Soc Care Community. 2011;19(4):438-448.

22. World Health Organization. Ageing and life course. Geneva: WHO; 2002. 